\title{
РЕАЛИЗАЦИЯ ПРАВОВОГО СТАТУСА ДЕКЛАРАНТА - ПЛАТЕЛЬЩИКА ТАМОЖЕННЫХ ПЛАТЕЖЕЙ В СВЕТЕ СУДЕБНЫХ РЕШЕНИЙ
}

\author{
(C) 2020 Матвиенко Галина Владимировна \\ кандидат юридических наук, доцент, \\ профессор кафедры правового обеспечения экономической деятельности \\ Российский государственный университет правосудия (РГУП), Россия, Москва \\ E-mail: galina7772005@yandex.ru
}

В статье освещаются актуальные проблемы реализации прав и исполнения обязанностей плательщиков таможенных платежей с учетом материалов судебной практики и правовой позиции высших органов правосудия. Отмечена взаимосвязь прав и обязанностей декларанта, реализуемых на каждой стадии таможенного процесса, с контрольными полномочиями таможенных органов: в ходе отправления формальностей, таможенного обложения, в рамках отношений, связанных с пользованием преимуществами таможенной процедуры, таможенного контроля после выпуска. Вносятся предложения по совершенствованию норм таможенного права и унификации судебной практики на территории ЕАЭС в целях повышения эффективности защиты прав декларанта.

Ключевые слова: Правовой статус, права и обязанности, таможенное обложение, декларант плательщик таможенных платежей, защита прав декларанта -плательщика таможенных платежей.

В юридической науке о содержательном наполнении правового статуса сказано немало. Анализируя особенности правового положения плательщиков таможенных платежей в рамках настоящей статьи сосредоточимся, прежде всего, на вопросах реализации субъективных прав, обеспечении исполнения публично-правовых обязанностей при позитивном взаимодействии таможни и декларанта с учетом новелл правоприменения.

Иные элементы правового статуса такой категории плательщиков, вопросы принудительного взыскания и возврата излишне уплаченных (взысканных) сумм мы оставим в стороне ввиду ограниченных рамок настоящей работы. Кроме того, в настоящем исследовании речь идет исключительно о таможенных платежах, тогда как в разделе II Таможенного кодекса ЕАЭС [1] урегулированы вопросы исчисления иных платежей - специальных, антидемпинговых и компенсационных пошлин, также администрируемых таможенными органами.

Традиционно обязанность уплатить таможенные платежи возлагается на декларанта, поскольку именно он является универсальным субъектом таможенных правоотношений. Между тем такая публично-правовая обязанность может возлагаться и на иных лиц, например на международных перевозчиков, владельцев складов временного хранения и иных лиц. Все они наряду с декларантом охвачены в таможенном законодательстве термином «плательщик».

В таможенном праве используется дифференцированный подход к определению статуса ординарных участников производства таможенного обложения, связанного с позитивным взаимодействием фиска и плательщика. Это проявляется в том, что законодатель указывает момент возникновения и прекращения обязанности по уплате таможенных пошлин и налогов, специальных защитных, антидемпинговых и компенсационных пошлин либо обеспечения такой уплаты. Этот момент зависит от характера осуществляемых с товаром таможенных операций в ходе производства таможенного оформления, а также типа избираемой таможенной процедуры [1, п.1 ст. 54].

Например, при ввозе товара обязанность по уплате у перевозчика возникает в момент пересечения грузом таможенной границы [1, п. 1 ст. 91]. По общему правилу такая обязанность прекращается при доставке товара в место назначения [1, п. 2 ст. 91]. Кроме того, Кодекс содержит и иные, общие для любых плательщиков основания для прекращения обязанности, например, уплата установленных платежей, а также случаи, когда такая обязанность не возникает.

Кодекс не содержит нормы, исчерпывающим

*Статья соответствует специальностям ВАК: 12.00.04; 12.00.14 
образом отражающей все права и обязанности декларанта, в том числе выступающего в роли лица, ответственного за уплату. Они установлены в разных разделах Кодекса, Закона о таможенном регулировании [25], Налогового кодекса РФ [5]. Таким образом, очевидна взаимосвязь юридических процедур таможенного обложения, отправления формальностей, таможенного контроля и таможенных процедур как составных элементов таможенного процесса.

Основы правового статуса декларанта заложены в ст. 84 TК ЕАЭС. Расположена она в разделе, посвященном таможенным операциям (прежде всего, отправлению формальностей). Однако большинство из указанных в ней прав и обязанностей тесно сопряжены с исполнением декларантом основной публично-правовой обязанности - уплатить таможенные платежи, специальные защитные, антидемпинговые и компенсационные пошлины. Так, к обязанностям декларанта в числе других относятся: уплата или обеспечение уплаты (например, при выборе льготной таможенной процедуры); подача таможенной декларации и иных документов на товар. В первой содержится информация о таможенных и иных платежах, подлежащих уплате. K числу иных документов законодатель относит подтверждающие уплату или обеспечение уплаты, право на льготы, таможенную стоимость товара и иные [1, ст. 108].

Применяемые в ходе выпуска товаров (завершающей стадии производства таможенного оформления), а также после выпуска, формы таможенного контроля (проверка документов и сведений, таможенная проверка), служат своеобразным инструментом обеспечения исполнения базовой обязанности декларанта - уплатить таможенные платежи.

Как правило, такие проверочные действия совершаются в связи с выявлением фактов недостоверного декларирования, в частности кода ЕTH ВЭД, а также таможенной стоимости. Заметим, что споры возникают как в ходе добровольного исполнения обязанностей плательщиками, так и в случае взыскания по результатам таможенных проверок, в связи с чем, декларанты нередко обращаются в суд. Причинами могут послужить действия сотрудников таможенных органов, а также принятые в развитие положений ТК ЕАЭС и иных нормативных актов, разъяснения Евразийской экономической комиссии, ФТС России.
Тем более важно наличие двух уровней защиты субъективных прав декларанта на территории страны и в рамках ЕАЭС: административный и судебный. Это гарантирует наличие соответствующих закону условий для исполнения декларантом-плательщиком публичноправовой обязанности по уплате таможенных и иных предусмотренных Кодексом платежей.

Пример: Евразийская экономическая комиссия разъясняет порядок применения Основных правил интерпретации ЕТН ВЭД, которые позволяют декларанту сориентироваться в классификации товара и определить код ЕТН ВЭД в целях таможенного обложения. Пояснения к ЕТН ВЭД необходимы на тот случай, если у декларанта возникают сомнения, к какому классификационному коду или группе товаров относится перемещаемый им груз. Последовательное применение Основных правил позволяет верно определить товарную позицию. Разъяснения, ограничивающие декларанта в возможности использовании Правил последовательным обра3ом, противоречат мировым стандартам [20; 24], нарушают принцип определенности в таможенном обложении, исключают полноценную реализацию правового статуса плательщика.

Особое влияние на правоприменителя в вопросах классификации оказывают т.н. «мягкие» нормы. В целом, это типично для регулирования таможенных отношений, импульсом для возникновения которых служит частный интерес в перемещении товара, и встречный публичный интерес в пополнении казны. В регулировании таких отношений без обобщения правоприменительной практики и рекомендаций экспертов не обойдись. Поскольку Россия является участницей Конвенции о Гармонизированной системе описания и кодирования товаров, и не отказалась воспринимать рекомендации соответствующего Комитета Всемирной таможенной организации, Верховный Суд РФ поясняет: в целях единства правоприменения при вынесении решения по спорной товарной позиции, обеспечения прозрачности и объективности в определении ставки таможенной пошлины, которой соответствует классификационный код, судам рекомендовано обращаться к рекомендациям о классификации соответствующих товарных позиций, разработанных международными организациями, к классификационным решениям таможенных органов зарубежных стран. Однако, суд не связан такими решениями и реко- 
мендациями - они не имеют для него заранее установленной силы. Окончательное решение должно быть вынесено с учетом всех обстоятельств [15, абз.2 п. 22].

Примеров судебной практики по данной категории таможенных споров немало, она широко освещается в научной литературе. Заметим, что суды в ряде случаев не принимают во внимание рекомендации международных организаций. Среди известных примеров - спор о классификации т.н. «умных» часов. В разрешении спора Верховный Суд РФ поддержал позицию декларанта, отменяя решения нижестоящих судебных инстанций, вынесенные в пользу казны. Таким образом, ставка таможенной пошлины оказалась гораздо ниже той, на которой настаивала таможня [7].

Приведу здесь еще один пример - из не нашумевших. В Россию ввозятся ричстакеры разновидность погрузчиков, которые используются при погрузке-разгрузке всех типов контейнеров, прицепов в портах, на железной дороге и в тяжелой промышленности. Несмотря на имеющиеся Поправки к Сборнику Классификационных мнений (37-я сессия ВТО, март 2006 года) о классификации ричстакеров, суд может принять противоположные по сути решения: в одном случае поддержать декларанта [11; 13], поскольку описание товара соответствует отраженному в вышеприведенном Сборнике (и в таких случаях применимы тарифные льготы), в другом - нет [10; 19].

Основной для исчисления таможенных платежей является таможенная стоимость, также подлежащая обязательному декларированию. Нормативной основой ее оценки в настоящее время являются: глава 5 ТК ЕАЭС, а также ряд нормативных актов Комиссии [например, 21; 22], глава 5 Закона о таможенном регулировании и подзаконные акты.

Обозначим некоторые моменты, важные в реализации прав и обязанностей плательщика в связи с оценкой таможенной стоимости.

Законодатель (и это неоднократно подтверждал Верховный Суд РФ) исходит из презумпции достоверности заявленной декларантом информации. Отсюда - возможность выпуска спорного товара под обеспечение, и одновременное требование для декларанта предоставлять достоверную, количественно определяемую и документально подтвержденную информацию о таможенной стоимости (а для таможни - мо- тивированно обосновать обратное в ходе дополнительной проверки и в суде). В постановлении Пленума Верховного Суда РФ от 26 ноября 2019 г. № 49 указано: бремя опровержения информации о таможенной стоимости и о правильности выбора метода ее оценки возложено на таможенный орган ввиду публично-правового характера отношений [15, абз. 2 п. 8].

K признакам недостоверности заявленной таможенной стоимости, которые могут стать предметом внимания таможни как в ходе выпуска, так и после, относятся: несоответствие сведений, содержащихся в одном и том же документе или отражаемых в иных прилагаемых документах друг другу, а также сведений, документов и информации, находящиеся в распоряжении таможенных органов (например, в информационной системе); указание более низкой цены товара (здесь варианты разнообразны - от сравнения с ценой идентичных и однородных товаров до сопоставления стоимости готовой продукции с ценой компонентов, из которых товар состоит); наличие взаимосвязи участников сделки, если это обстоятельство оказало влияние на снижение стоимости; несоблюдение структуры таможенной стоимости (например, не добавлены к контрактной цене расходы на транспортировку, лицензионные платежи и иные дополнительные начисления) [22, пункт 5].

В правовой позиции, изложенной ранее в абз. 3 п. 5 Постановления Пленума ВАС РФ от 26 июля 2005 г. № 29 [14; 17], впервые проявился паритет частного и публичного интересов. С одной стороны, таможня вправе затребовать только те документы, подтверждающие стоимость товара, которыми декларант должен располагать силу закона и с учетом обычаев делового оборота. С другой стороны, непредставление истребованных документов следует рассматривать в качестве несоблюдения условия достоверности, количественной определенности и документальном подтверждении таможенной стоимости лишь в том случае, когда такие документы имеют значение для таможенного оформления и определения таможенной стоимости товара [см. 17]. Подобная формула и в современный период активно применяется в арбитраже [14], хотя прямо не отражена в новых пояснениях Верховного Суда РФ [15; см. также 6].

Поскольку оценка таможенной стоимости декларантом и таможенным органом сопряжена с применением сравнительных величин (стои- 
мости товаров по цене сделки с идентичными и однородными товарами). Нередко у первого нет доступа к информации о сделке конкурентов. Отсутствие у плательщика реальной возможности применить такие величины для сравнения становится «камнем преткновения».

Признаки недостоверности, по мнению Суда, таможня может усмотреть в значительном различии цены ввезенного товара с ценой сделки с идентичными и однородными товарами. Однако если такая информация отсутствует в таможенном органе, он вправе воспользоваться данными официальных и иных общепризнанных источников информации, а также товарноценовых каталогов [15, абз. 3 п. 10]. Понятно, что так решается проблема оценки стоимости таможенным органом в случае ее возможной корректировки. Между тем, действующее таможенное законодательство по-прежнему не содержит требования для таможенных органов публиковать проверочные величины.

Очевидно, в ближайшее время споры об оценке таможенной стоимости не прекратятся ввиду оценочности последней. И в рамках настоящей работы проанализирована лишь мизерная их доля.

Общие права декларанта [1, ст. 84] касаются преимущественно осуществления таможенных операций с товарами (например, присутствие при таможенном досмотре). Однако их реализация тесным образом связана с обязанностью предоставить фиску своевременно достоверную и полную информацию о грузе в целях таможенного обложения.

Таким образом, обязанности декларантаплательщика связаны с осуществлением в отношении него полномочий контрольно-надзорного характера.

Большой объем прав декларанта в рамках производства таможенного обложения, связанного с добровольной уплатой таможенных платежей, установлен в разделе II TK ЕАЭС и разделе II Закона о таможенном регулировании - «Таможенные платежи, специальные, антидемпинговые и компенсационные пошлины».

Достаточно удачной представляется предложенная в науке классификация прав налогоплательщика, которая может быть воспринята и при анализе практики применения норм о таможенном обложении [4, С. 82-90]:

1. Право на информирование об установлении, введении и порядке уплаты таможен- ных платежей. Так, частью 2 ст. 264 Закона о таможенном регулировании предусматривается возможность получения консультации по вопросам таможенного дела в устной, в письменной, а с 1 января 2020 года - и в электронной формах; ФТС России обязана публиковать в своих официальных изданиях акты, принятые в развитие положений таможенного законодательства, международных норм о таможенном деле и изменений в национальное таможенное законодательство.

Кроме того, лицо вправе получить по запросу информацию о причинах принятых таможней решений, совершенных действий либо бездействия [25, ст. 265].

Полагаю, в этой части в рамках ЕАЭС возможна рецепция позитивного опыта Европейского Союза, в котором создана специальная интернетплатформа, объединяющая работу всех органов государственной власти стран-участнии, и позволяющая резиденту государства Союза в режиме единого окна обжаловать, к примеру, действия сотрудника таможни другого государства -члена EC [26].

2. Права плательщика таможенных платежей в сфере исполнения публично-правовой обязанности по уплате. К ним традиционно причисляются право уплаты только установленных налогов, право на использование льгот по уплате, право на досрочное исполнение обязанностей, право на возврат излишне взысканных платежей и др.

Проанализируем отдельные права этой группы применительно к таможенному обложению:

2.1. Право уплаты только установленных таможенных платежей, основанных на унифицированной процедуре их исчисления. Перечень таможенных платежей содержит ст. 46 ТК ЕАЭС: таможенные пошлины, импортные налоги - НДС, акцизы и таможенные сборы. Юридический состав ввозных таможенных пошлин регламентирован преимущественно наднациональными нормами [1, раздел II; 23]; состав вывозных таможенных пошлин [16], косвенных налогов устанавливается национальным законодательством [5, ст.ст. 151, 160, 164; ст. 181, 184-187.1, 191, 193.1], равно как виды и юридический состав таможенных сборов [25, гл. 8]. Очевидно, что в странах ЕАЭС виды таможенных платежей должны быть идентичными.

2.2. Декларант имеет право на дифференццированный подход к форме и способам уплаты 
таможенных платежей. Пример: получатели международных почтовых отправлений вправе воспользоваться новыми технологиями и уплатить таможенные платежи с использованием программных средств и технических устройств в рамках платежной системы, оператором которой является оператор таможенных платежей, либо уплатить таможенные платежи в наличной форме в кассе федеральной почтовой связи. Печальный опыт показывает: нередко кассы не работают, а безналичный расчет возможен посредством дебетовых карт определенных платежных систем (например, к оплате не принимаются карты «МИР»), что препятствует своевременному исполнению обязанности и вынуждает декларанта помещать товар на СВX, т.е. платить за хранение.

2.3. Как и любой иной плательщик, декларант имеет право: выбирать способ обеспечения уплаты таможенных платежей [1, абз. 3 п. 3 ст. 63]. На практике таможня охотнее всего идет навстречу лицу, претендующему на такие способы обеспечения уплаты, как денежный залог, гарантия. Реже применяются поручительство и залог иного имущества. Объясняется это тем, что процедура обращения взыскания на денежное имущество должника упрощена. $B$ таможенном деле не применяется страхование, а также залог ценных бумаг. Как показывает зарубежный опыт, разнообразие способов обеспечения уплаты способствует ускорению таможенного оформления.

2.4. При наличии оснований плательщик имеет право на перенесение таможенным органом срока их уплаты [25, гл. 9]. К сожалению, национальное законодательство не предусматривает возможности получения отсрочки в уплате таможенных сборов, тогда как взыскиваются такие платежи таможней принудительно по правилам взыскания таможенных пошлин и налогов. Такой подход нарушает паритет частных $u$ публичных интересов.

2.5. Право на получение льгот в части таможенного обложения.

Пункт 1 ст. 49 ТК ЕАЭС устанавливает перечень возможных льгот по таможенным платежам: по уплате импортных пошлин (т.н. тарифные льготы, предусмотренные Договором о Союзе); по уплате экспортных пошлин (устанавливаются на уровне национальном); льготы по уплате налогов (предусмотрены в национальных налоговых кодексах); льготы по уплате таможенных сборов в форме освобождения от уплаты (регламентированы в национальных законах о таможенном регулировании и подзаконных актах).

Льготы характеризуют особенности правового статуса декларанта, но в рамках конкретного случая перемещения товаров.

3. В области учета и контроля за уплатой таможенных платежей декларант и иные плательщики также наделяются особыми правами.

Так, подконтрольное лицо вправе знакомиться с материалами таможенной проверки после получения акта о ее проведении; представлять возражения по акту таможенной проверки [25, п. 2, 3 ст. 235]; обжаловать действия (бездействия) сотрудников таможни [25, гл. 51].

На декларанта как плательщика косвенных налогов, взимаемых при ввозе товаров, возлагаются общие для налогоплательщиков права $\boldsymbol{u}$ обязанности, установленные Налоговым кодексом РФ и отражающие базовый правовой статус, а также особые права и обязанности, характеризующие изъятия из общеправового статуса (специальный правовой статус) [2, С. 137138; 4, С. 80].

Общие обязанности налогоплательщика, по мнению ученых, связаны в основном с осуществлением в отношении них полномочий по контролю (предоставлять налоговую декларацию, вести учет деятельности по общепринятым формам, хранить документы налогового контроля, предоставлять сведения) [4, С. 82-83]. В таможенном деле права и обязанности декларанта как подконтрольного лица также играют немаловажную роль. Если процесс взаимодействия таможни и декларанта представить в качестве совокупности юридических производств и процедур, организованных последовательно в целях достижения искомого результата,- помещения товара под определенную таможенную процедуру, окажется, что контрольные мероприятия предшествуют перемещению товара и применяются даже после выпуска (завершения формальностей). Контроль «пронизывает» все стадии взаимодействия декларанта и таможни.

Немаловажный признак правового статуса декларанта заключается в том, что права и обязанности взаимообусловлены, тесно связаны между собой. На каждой стадии взаимодействия декларант выступает в роли подконтрольного лица и одновременно соискателя таможенной процедуры (в производстве таможенного 
оформления), плательщика (производстве таможенного обложения), пользователя преимуществами таможенной процедуры, лица, подвергаемого таможенному контролю после выпуска. Его статус модифицируется в зависимости от задач взаимодействия с таможней. Защите, между тем, подлежат все права декларанта, во всем многообразии его правовых модусов.

Из новых примеров судебной практики, подтверждающих данный тезис, можно привести следующий. В Россию ввезены биологически активные добавки, товар помещен под процедуру «выпуск для внутреннего потребления». У декларанта возникают сложности в реализации партии товара ввиду его ненадлежащего качества, поэтому он подает таможенную декларацию в целях реэкспорта, затем - по требованию таможни - заявление о помещении товара под указанную процедуру. Последняя позволяет декларанту вернуть уплаченные ранее ввозные таможенные пошлины и налоги, т.е. является льготной. Таможня отказывает выпуске товара в соответствии с заявленным режимом, фактически вынуждая декларанта, связанного контрактными сроками возврата товара поставщику, поместить товары под таможенную процедуру экспорта. Соответственно таможенные платежи, уплаченные ранее при выпуске в свободное обращение в размере более 7 млн. руб., возвращать таможня отказалась. Не будем здесь останавливаться на мотивировочной части всех судебных решений по этому делу, обратим внимание лишь на пояснения Судебной коллегии по экономическим спорам Верховного Суда РФ, по мнению которой суд первой и апелляционной инстанции правомерно возложили на таможенный орган обязанность по возврату таможенных пошлин и налогов заявителю. Суд округа [12], напротив, указал, что таможенная процедура реэкспорта фактически реализована не была, и у общества, не воспользовавшегося своим правом на оспаривание отказа в выпуске товара в соответствии с заявленной процедурой и впоследствии поместившего товар под таможенную процедуру экспорта, не возникло право на возврат излиш- не уплаченных таможенных платежей. Вернуть их возможно, по мнению суда округа, только в порядке искового производства как убытки.

Верховный Суд РФ пояснил: такой подход противоречит смыслу положений ст. 46 Конституции РФ (гарантии каждому на судебную защиту), Конвенции о защите прав человека и основных свобод и положениям пункта 2 ч. 1 ст. 29, ч. 1 ст. 198 АПК РФ, в которых также предусмотрено право субъекта предпринимательской деятельности защищать свои права в порядке административного судопроизводства и оспорить соответствующие ненормативные акты таможенных органов. Коллегия пояснила: «суд округа по существу обусловил невозможность восстановления прав заявителя теми действиями таможенного органа, которые являются незаконными и в отношении которых заявитель испрашивал судебной защиты» [8].

В целом, вопросы возврата таможенных платежей требуют, конечно, более глубокого анализа.

Подведем итоги. Эффективной реализации правового статуса декларант-плательщика таможенных платежей способствуют разнообразные упрощения формальностей: применение электронного декларирования, удаленного выпуска и сопутствующей ему технологии удаленной уплаты таможенных платежей; общение с таможенным органом через личный кабинет, получение консультации в электронной форме, возможность подачи электронной жалобы и иные блага цивилизации в цифровой век. Между тем, защита прав декларанта-плательщика таможенных платежей по-прежнему невозможна без выработки единых подходов правоприменения, чему много лет способствуют Конституционный и Верховный суды РФ. Очевидно, пора объединять усилия высших органов правосудия стран Союза под эгидой Евразийского экономического суда, наделив его полномочиями общения судебной практики на всей территории интеграционного образования и выработке единой правовой позиции по вопросам применения Таможенного кодекса ЕАЭС.

\section{Библиографический список}

1. Договор о Таможенном кодексе Евразийского экономического союза (Подписан в г. Москве 11 апреля 2017 г.) (приложение № 1- Таможенный кодекс ЕАЭС) // Официальный сайт Евразийского экономического союза http://www.eaeunion.org/, 12.04.2017

2. Загряцков М. Д. Административная юстиция и право жалобы в теории и законодательстве. М., 1925. 
3. Закон РФ от 21 мая 1993 г. № 5001-3 «О таможенном тарифе» (с изм. и доп., включая от 18 февраля 2020 г.) // Ведомости СНД и ВС РФ. 1993. № 23. Ст. 821

4. устова М.В., Ногина О. А., Шевелева Н. А. Налоговое право России. Общая часть: учеб. / отв. ред. Н.И. Шевелева. М., 2001.

5. Налоговый кодекс РФ (ч. 2) от 5 августа 2000 г. № 117-ФЗ (с изм. и доп., включая от 28 января 2020 г.) // СЗ РФ. 2000. № 32. Ст. 3340.

6. Определение Верховного Суда РФ от 09 июля 2019 г. № 308-ЭС19-10260 по делу № А32-12797/2017 (Об отказе передачи дела для пересмотра в кассационном порядке судебных актов по делу по заявлению об обязании таможенного органа возвратить таможенные платежи, излишне взысканные по спорным; суды, удовлетворяя требования, исходили из доказанности заявителем предоставления в обоснование таможенной стоимости пакета документов, необходимого для применения основного метода таможенной оценки, и недоказанности таможней обратного) // СПС «КонсультантПлюс».

7. Определение Судебной коллегии по экономическим спорам Верховного суда РФ от 20 сентября 2017 г. № 305-КГ-3138 по делу № A40-32818/2016 (Об удовлетворении требования, содержащегося в кассационной жалобе и отмене судебных актов и признании предварительных решений по классификации товаров, вынесенных таможней, незаконными) // СПС «КонсультантПлюс».

8. Определение Судебной коллегии по экономическим спорам Верховного Суда Российской Федерации от 26 февраля 2020 г. № 307-ЭС19-20834 по делу № А66-5520/2017 (Об удовлетворении требования общества, содержащегося в кассационной жалобе, и обязании Московской областной таможни возвратить излишне уплаченные таможенные платежи в связи с неправомерным отказом в применении таможенного режима реэкспорта, что привело к необоснованной уплате таможенных платежей. Требование удовлетворено, так как суды первой и апелляционной инстанций правомерно возложили на таможенный орган обязанность по возврату ввозных таможенных пошлин и налогов заявителю; суд округа, по существу, обусловил невозможность восстановления прав заявителя теми действиями таможенного органа, которые являются незаконными и в отношении которых заявитель испрашивал судебной защиты) // СПС «КонсультантПлюс»).

9. Постановление Арбитражного суда Дальневосточного округа от 29 августа 2019 г. № Ф03-3449/2019 по делу № A59-7205/2018 (Об удовлетворении требования о признании незаконным решения таможни о таможенной стоимости товаров, поскольку обществом правомерно определена таможенная стоимость по стоимости сделки с ввозимыми товарами, достоверность цены товара подтверждена надлежаще оформленными документами) // СПС «КонсультантПлюс».

10. Постановление Арбитражного суда Московского округа от 03 мая 2017 г. № Ф05-4026/2017 по делу № А40142978/16-149-1227 (Об отказе в удовлетворении кассационной жалобы общества на судебные решения о классификации ричстакеров, вынесенные в пользу таможенного органа и оставлении судебных актов без изменения) // СПС «КонсультантПлюс».

11. Постановление Арбитражного суда Московского округа от 04 мая 2017 г. № Ф05-2541/2017 г. по делу № A40-133656/2016 (Об отказе в удовлетворении кассационной жалобы таможенного органа на судебные решения по вопросу классификации ричстакеров и оставлении решений без изменения) // СПС «КонсультантПлюс».

12. Постановление Арбитражного суда Северо-Западного округа от 29 августа 2019 г. № Ф07-8937/2019 по делу № A66-5520/2017 (О частичном удовлетворении требования о признании незаконным решения об отказе в применении режима реэкспорта, и об отказе во взыскании излишне уплаченных таможенных платежей, поскольку таможенная процедура реэкспорта реализована не была; в целях соблюдения сроков возврата товар вывезен в режиме экспорта; оснований для возврата таможенных пошлин не возникло; обществом избран ненадлежащий способ защиты права) // СПС «КонсультантПлюс».

13. Постановление Девятого арбитражного апелляционного суда от 16 января 2017 г. № 09 АП-61432/2016-АК по делу № A40-133656/16 (Об оставлении решения арбитражного суда без изменения, а апелляционной жалобы таможенного органа по вопросу классификации ричстакеров - без удовлетворения) // СПС «КонсультантПлюс».

14. Постановление Пленума Высшего Арбитражного Суда РФ от 26 июля 2005 г. № 20 «О некоторых вопросах практики рассмотрения споров, связанных с определением таможенной стоимости товаров» // Вестник ВАС РФ. 2005. № 12 (документ утратил силу).

15. Постановление Пленума Верховного Суда РФ от 26 ноября 2019 г. № 49 «О некоторых вопросах, возникающих в судебной практике в связи с вступлением в силу Таможенного кодекса Евразийского экономического союза» // Рос. газета. 2019. 06 дек. 
16. Постановление Правительства РФ от 30 августа 2013 г. № 754 «Об утверждении ставок вывозных таможенных пошлин на товары, вывозимые за пределы государств - участников соглашений о Таможенном союзе, и признании утратившими силу некоторых актов Правительства РФ» (в изм. и доп., включая от 07 сентября 2019 г.) // СЗ РФ. 2013. № 36. Ст.4582.

17. Постановление Президиума Высшего Арбитражного Суда РФ от 19 апреля 2005 г. № 13643/04// СПС «КонсультантПлюс».

18. Постановление Пятнадцатого арбитражного апелляционного суда от 5 февраля 2014 г. № АП-15848/13. (Об отказе в удовлетворении апелляционной жалобы Находкинской таможни и оставлении решения арбитражного суда без изменения: требования таможни по предъявлению документов в целях подтверждения таможенной стоимости ограничены объективной возможностью декларанта представить такую информацию. Мотивированный отказ, направленный таможне в письменной форме, не освобождает таможенный орган от необходимости провести дополнительную проверку и не позволяет скорректировать таможенную стоимость произвольно) // СПС «КонсультантПлюс».

19. Постановление Пятого арбитражного апелляционного суда от 26 апреля 2018 г. № 05АП-1819/2018 по делу № A51-25676/2016 (Об отказе в удовлетворении апелляционной жалобы общества на решение арбитражного суда, вынесенное в пользу таможенного органа по вопросу классификации ричстакеров, и оставлении решения арбитражного суда без изменения) // СПС «КонсультантПлюс».

20. Решение Апелляционной палаты Суда Евразийского экономического сообщества от 21 февраля 2013 г. «Об оставлении без изменения Решения Суда Евразийского экономического сообщества от 15.11.2012, которым было признано не соответствующим международным договорам, заключенным в рамках Таможенного союза, Решение Комиссии Таможенного союза от 18.10.2011 N 819 «О классификации в соответствии с единой Товарной номенклатурой внешнеэкономической деятельности Таможенного союза транспортных средств МТЛБ, МТПЛБ, ТГМ» // Бюллетень Суда ЕврАзЭС. 2013. № 1.

21. Решение Коллегии ЕЭК от 16 октября 2018 г. № 160 «О случаях заполнения декларации таможенной стоимости, утверждении форм декларации таможенной стоимости и Порядка заполнения декларации таможенной стоимости» (в ред. от 21 мая 2019 г.) // СПС «КонсультантПлюс»;

22. Решение Коллегии ЕЭК от 27 марта 2018 г. № 42 «Об особенностях проведения таможенного контроля таможенной стоимости товаров, ввозимых на таможенную территорию Евразийского экономического союза» (вместе с «Положением об особенностях проведения таможенного таможенной стоимости товаров, ввозимых на таможенную территорию Евразийского экономического союза») // СПС «КонсультантПлюс».

23. Решение Совета ЕЭК от 16 июля 2012 г. № 54 «Об утверждении единой Товарной номенклатуры внешнеэкономической деятельности Таможенного союза и Единого таможенного тарифа Таможенного союза» (ред. от 16 марта 2020 г.) // СПС «КонсультантПлюс».

24. Решение Суда Евразийского экономического сообщества от 15 ноября 2012 г. «О признании не соответствующим международным договорам, заключенным в рамках Таможенного союза, Решения Комиссии Таможенного союза от 18.10.2011 N 819 «О классификации в соответствии с единой Товарной номенклатурой внешнеэкономической деятельности Таможенного союза транспортных средств МТЛБ, МТПЛБ, ТГМ» // СПС «КонсультантПлюс».

25. Федеральный закон от 03 августа 2018 г. № 289-Ф3 «О таможенном регулировании в Российской Федерации и о внесении изменений в отдельные законодательные акты Российской Федерации» (с изм. и доп., включая от 27 декабря 2019 г.) // СЗ РФ. 2018. № 32 (ч. І). Ст. 5082.

26. Regulation (EU) No 1024/2012 of the European Parliament and of the Council of 25 October 2012 on administrative cooperation through the Internal Market Information System and repealing Commission Decision 2008/49/EC ('the IMI Regulation') Text with EEA relevance /OJ L 316, 14.11.2012, p. 1-11. 